\title{
Citizenship Service Learning: Becoming Citizens by Assisting Immigrants
}

\author{
Robert Koulish, Bentley College
}

$\mathrm{C}$ itizenship Service Learning (CSL) serves to reinforce the strengths inherent in the traditional principles of higher education while concurrently transcending its limitations. CSL principles are celebrated on two grounds. The first is pedagogical. Following liberal arts traditionalists, CSL adheres to the classroom as a site for developing cognitive skills through accumulating information and learning research methods. It then stretches the learning process into the civic arena, where students gain tools in problem solving, critical thinking, leadership, and team work through the experience of working with immigrants.

CSL establishes the educational value of what William Kilpatrick (1918) refers to as the "Project Method," education centered around multifaceted, real-world problems, as opposed to compartmentalized subject matter. Through this pedagogic process, CSL coheres cross-disciplinary service learning (see Stember 1991) around a common programmatic theme, the process of gaining citizenship.

Second, CSL's view of citizenship accounts for and then transcends the formal view of legal-status citizenship. Legal-status citizenship provides an individual with full membership in the political community, access to equal voting, holding office, unencumbered travel abroad, and entitlement to scarce public re-

\footnotetext{
Robert Koulish, is assistant professor of government at Bentley College. He is Director of the Bentley Immigrant Assistance Program (BIAP), and Associate Director Bentley Service Learning Center (BSLC). He has written on immigration at the U.S.Mexico Border in NYU Law Review of Social Change, immigration and human rights in a working paper series published by the University of Arizona, published an article in the Journal of the Rio Grande, and on service learning issues in Teaching Sociology, published in April 1998.
}

sources. CSL transcends this ostensibly passive, rights-oriented citizenship for an active, communitycentered citizenship. As community membership and class grades come to rely on the students' performance, students become stakeholders in the classroom and civic process beyond. ${ }^{1}$

The two virtues that have been claimed for CSL are related. Scholars from Alexis de Toqueville to Benjamin Barber have claimed that education should serve as a training ground for citizenship. At issue is the type of education and citizenship that results: a traditional pedagogy that trains students for a type of citizenship that is passive, demanding no specific proactive behavior on the part of students or citizens, or one that encourages and provides tools for proactive involvement. Following de Toqueville, and Barber, CSL encourages pedagogy for civic involvement.

I devote this article to a discussion of CSL. The article outlines the fundamental characteristics of CSL, a pedagogic model of CSL currently implemented at one college in New England, and discusses and assesses the role and benefits of a CSL program. ${ }^{2}$

\section{Citizenship Service Learning}

CSL trains young people in the ways of the self- and socially-creative intentional public being (Wright 1989; see also Becker and Couto 1996; May and Koulish 1998). Students gain the tools for effective public involvement in the process of preparing immigrants for legal-status citizenship. They develop the skills of citizenship by conceptualizing different CSL projects, designing and managing projects, planning activities, delegating responsibilities, communicating with peers and the media, reaching out to multicultural immigrant communities to organize events along with community-based organizations (CBOs), and engaging immigrants in dialogue about citizenship (Farr 1997). Students also develop a better sense of their own identities through contact with immigrants, often filling gaps in their own biographies. All that occurs while students receive course credit, and become more marketable with the skills they have just gained.

Concurrently, CSL students ready immigrants for legal-status citizenship by providing English as a Second Language (ESL) discussion groups, and citizenship classes in U.S. government and history, all of which provide skills required for naturalization. Immigrants also gain expert assistance in completing their $\mathrm{N}-400$ applications for citizenship as well as opportunities to contribute their experiences and knowledge capital to students and other immigrants.

CSL expands upon service learning pedagogy while making use of its fundamental principles. CSL's initial focus outside the classroom is on community service, broadly defined as the application of a student's knowledge capital to provide something of value to enhance the quality of life of people who articulate a need or desire for that service (Cruz 1997). Collaboration with CBOs exposes students to localized power where the locus of decision making resides with them and their peers in the neighborhood (Kymlicka and Norman 1994, 359; MacKnight 1995). CSL encourages students to engage the polity on a smaller and more human scale. Citizenship becomes more accessible and its effects are more immediate.

In itself, the benefits of student involvement in community service are limited. It is wrong-headed to presume that students should gain such broad civic lessons in public responsibility, accountability, and 
toleration solely through working in a CBO. The organization's narrowly tailored mission and constituency mitigate against the inculcation of such broad civil values (Kymlicka and Norman 1994; Pierson 1991).

Community service should instead be integrated within the academic curriculum. Experiential education connects community service to the classroom. It connects knowledge to experience, is problem-centered, and is grounded in the depth of meaning that attaches to its coming within urgent daily interests (Dewey 1916, $8)$. In other words, experiential education is personal and active, a process of learning by doing, and is a reflective component upon such fullbodied involvement and experience with things (May and Koulish 1998; Hutchings and Wutzdorff 1988).

Participation in the community and reflection upon that experience serves as the basis for service learning, a practice of learning which is integrated within an intentionally designed course, program, or activity (Cruz 1997). Contemporary scholars claim that service learning enhances the fundamental goals of higher education. James Coleman (1978), argues that service learning is critical for the "creation of a solid experience base for the very symbolic media that are subsequently used to transmit information." Ernest Boyer (1987) suggests that by appealing to the practicalities of a student's career upon graduation, professors may motivate students to take a more proactive stance towards learning.

CSL adds an interactive component to community, connecting both campus (faculty, staff, and students across disciplines) and neighborhood (CBOs and immigrants) though real world and even virtual realities (teleconferencing and interactive websites). It is common for CSL students to come from classes in several different departments. It is similarly common for the same CSL students to conduct work at several community sites. CSL views the campus and community as equal partners, following Harkavy and Pukett's credo to "work and study with the community; never study them as mere pa- tients, subjects, or other unredeemable persons to collect data about" (1992, 32).

Whereas service learning provides opportunity for personal growth and development of self confidence (Battistoni and Hudson 1997), CSL students grow through public involvement. They assume leadership in matters of policy, interact with neighbors as equals, and establish a concrete connection between the rights and responsibilities of citizenship (Barber 1997, 229). Throughout the process, scheduled classroom meetings remain an integral forum for evaluation of the students' cognitive development and problem-solving skills, for discussion and inquiry.

\section{Bentley Immigrant Assistance Program: A Case Study}

Bentley College, through its Bentley Service Learning Center (BSLC), has worked successfully with a wide range of community-based organizations and boasts one of the country's most active service learning centers. As a Bentley College priority, the BSLC is ever vigilant for new and more effective ways of helping students become productive citizens. By adopting CSL methods, the Bentley Immigrant Assistance Program (BIAP) represents just such a new direction.

BIAP consists of a centralized network of immigrant assistance projects to which faculty refers Bentley students and $\mathrm{CBO}$ s refer immigrant clients. Prior to the start of each semester, BIAP disseminates brochures and email distribution list queries to faculty across disciplines. Particular attention is paid to faculty already engaged in service learning, or who have expressed interest in CSL as well as those who have specific training in areas that would enhance program effectiveness. Such outreach results in the integration of BIAP projects with several course syllabi, ${ }^{3}$ course clusters, ${ }^{4}$ fourth credit options, ${ }^{5}$ directed studies, service learning internships and volunteering.

The recruiting of $\mathrm{CBOs}$ continues year-round through direct outreach as well as word of mouth. By collaborating in a partnership with the college, CBOs receive student capital at no cost to their immigrant clients. Bentley students serve as teachers, teaching assistants, and tutors for citizenship and ESL classes. CBOs provide immigrant-clients to the program and host CSL workshops and classes for prospective citizens. In addition to collaborating with the college in organizing particular events, immigration practitioners affiliated with $\mathrm{CBOs}$ provide seminars regarding the latest developments in naturalization regulations and procedures.

Immigrants are provided assistance in preparing and applying for citizenship. Through contact with college students, they gain a broader experience of their communities and often have the opportunity to recount aspects of their own biographies. Moreover, while students provide tangible assistance for immigrants, immigrants teach students about their own cultures and ways of living, thus assisting students in filling in the gaps of their own biographies. This active learning experience bridges the gulf between self and other. In the process of mutual teaching and learning, students and immigrants may even forge personal acquaintances and friendships, connecting public and private experience that results in real-life citizenship.

\section{CSL/BIAP Projects}

Students involved in BIAP engage immigrants who are on track to progress from the most temporary types of immigration status to citizenship. In the Political Asylum Project, for example, students provide assistance for immigrants whose legal status is temporary and tentative. ${ }^{6}$ In English as a Second Language (ESL) discussion groups ${ }^{7}$ and citizenship classes, ${ }^{8}$ students engage immigrants of all immigration statuses preparing for legally required citizenship exams. Finally, as discussed in the case study below, in providing face-to-face assistance naturalization assistance, students en- 
gage immigrants in the final stages of their journey towards citizenship.

\section{Citizenship Day}

This section highlights the cornerstone of BIAP's citizenship project called Citizenship Day (C-Day). CDay is a day-long session first held in April 1997 and now held once a semester. The C-Day project is a collaborative endeavor with multiple CBOs, where students assist immigrants in completing their packets for citizenship including N-400 application forms, fingerprints, and photos. Bentley undergraduates take nine hours of training to become naturalization associates. Expert immigration practitioners teach students about the legal requirements for naturalization, how to assist immigrants in completing applications, and, through role-playing Immigration and Naturalization Service (INS) interviews, to provide students with a real sense of what their responsibilities will be.

The project originated as part of my three-credit Politics of Immigration course, which requires service learning and also offers a fourth credit service learning option. Most students select the fourth credit, thus assuming responsibilities for an additional project and writing an additional paper integrating their service learning experience with the concepts and theories presented in class lectures. Students taking the course for three credits must complete a single service learning project that requires completing working for six hours as a naturalization advocate on C-Day. Students taking the fourth credit also serve on one of three committees preparing for $\mathrm{C}$ Day. The fourth credit option ostensibly allows for a more extensive CSL experience. All students must keep service learning journal entries in which they are asked to describe their service experience, detail personal reactions to the events, and connect their service with course readings and class discussions.

The C-Day event itself is held on a Saturday in one of the largest rooms in the student center. In April 1997, about one hundred immigrants arrived on campus and were guided to the student pavilion. The number of immigrant participants reached 140 in November 1997, and nearly 200 in April 1998. The immigrants sign in, receive numbers, and take their seats to await their turn at the prescreening table. After prescreening the immigrants move on to the application tables, where they meet one of the naturalization advocates. About five supervising immigration lawyers are on hand to respond to problems and questions that arise and to "eye-ball" each completed application. After their applications are completed, certified officials take passport-type photos and fingerprints of the immigrants. Day care is provided. Lunch and featured speakers-including students, immigrants, faculty, community representatives, and state and local politiciansmake for a festive celebration of citizenship in all its forms.

The months of preparation to get ready for Citizenship Day provide important CSL lessons. Certain patterns emerge from student development as pro-active citizens, from self-absorbed and hesitant to publicspirited and emboldened. During the first several weeks of the semester, after being introduced to the project, students are likely to give voice to fears about and perceptions of their own lack of competence. A particularly revealing statement focuses attention on a student's feelings of powerlessness.

I am quite uncertain about myself. I do not know if I am up to the challenge. I do not know what to expect. In class we discussed the different aspects as to what was going to go on, but I do not have any hands on experience. Our only knowledge is what we read, word of mouth and the diagrams we keep drawing on the board.... I just keep thinking what a big deal this is, I mean, important government papers where the future of somebody's life depends on making sure I do my job precisely. That's a lot of pressure.

Indeed, students find the project involves lots of pressure. There is nothing wrong with such feelings. The key factor in terms of the project is facing fears and struggling to overcome barriers. Students must be encouraged to voice their feelings of uncertainty as a first step toward overcoming them. One student wrote:

On a personal note, my main fear is the one that $I$ always have when facing something new ... failure. I have always gone into new things thinking to myself that I am going to do something wrong or something involving me will go wrong or screw up.

A second student voiced a similar concern:

I feel nervous and scared that I wasn't doing enough. ... It's as if I cannot do enough no matter how much I try.

Indeed, neither of these students had much experience in civic participation. Their fears are a sign of inexperience in civic work. During the several weeks that followed, however, both of these students underwent a similar transformation from awkward victim into a more selfconfident and proactive citizen. The students' journals also make clear that the process itself becomes a tool to enhance the students' education in proactive citizenship. As the second student reflected:

I feel that as time moves on, the others feel nervous just like me and we were all there to help one another. The close interaction of everybody working together for a common goal made me feel so good inside, it is unbelievable to see this event really begin to take shape ... we are all becoming friends ... we all care about what is going to happen.

Midway through the semester, students began acknowledging the values of interactions with others, a sign of students stretching beyond their own biography. By C-Day, students began expressing their connection to the larger community, thus also acknowledging the lure of CSL:

He (an immigrant) talked about his life when he came over here and how he worked in a candy factory in Cambridge. He gave us the advice of working as hard as we 
could so we can relax and have fun later on, and that learning different languages couldn't hurt. So many different cultures, there was no avoiding learning and inquiring from others about their own culture.

Indeed, the path to making students more effective, socially conscious citizens also provides the opportunity for students to transcend the barriers of their own biography to work collaboratively and begin to see the world as others experience it. By the latter stages of the process, the social distance diminishes between the "students" and "strangers" in the community. As a third student claimed of C-Day:

It wasn't anything like what many in the training sessions had us envision. I worked with one entire Armenian family and found myself in a regular conversation with them. As the day continued, I felt good that I was opening myself up to other cultures. I guess this was one of the goals of the whole project.

This particular student who had previously participated in some community service, was not aware he could have regular conversations with foreign-born residents until this event. For this student and others similarly situated, C-Day provides an introduction to a great mosaic of ethnic, racial, and religious difference.

Students opting for the fourth credit in particular also come to value their fellow students and the immigrant community as essential sources of knowledge. Students gain knowledge of Boston's present and, through research for the fourth credit paper, past immigrants. Several students' journals show them drawing connections based on their encounters with immigrants, between immigrant entrepreneurship and the greater Boston area's recent economic resurgence.

The work for C-Day is divided among three student-led committees: Logistics, Media, and Outreach. These committees convene in class and on the students' own time. The Logistics Committee is charged with securing the hall to be used for the event, finding local businesses to do- nate supplies and food, tacking up posters around campus, and preparing the hall with interview tables and decorations.

The Media Committee works with the college public relations office to contact representatives from local and regional TV, radio, and area newspapers. Prior to the first C-Day, more than one hundred area radio stations, including college and community stations that feature ethnic focused programs, were contacted. A committee member wrote:

\begin{abstract}
The media committee seemed a perfect match for me. I love to talk and sell and thought these talents would help me. Selling to the media turned out to be far more difficult and frustrating that I imagined. I called, I faxed and I e-mailed until I was blue in the face, and still didn't seem to be getting the results I wanted....
\end{abstract}

Still, two students managed to appear on Televisa, Spanish-language $\mathrm{TV}$, to talk about the event. Others sent out press releases and made dozens of follow-up phone calls to assure coverage of the event. The April 1997 session was covered by the campus newspaper and the Associated Press wire service. In each of the three C-Days, several students were interviewed and quoted in the local newspaper.

Members of the Outreach Committee work directly with CBO representatives and immigrants. Often working at $\mathrm{CBO}$ offices, they make contact with immigrants, hold workshops, poster off-campus locales, and, at the event itself, conduct the prescreening of immigrants. Some students in the outreach group embody characteristics of the proactive citizen from the start. As one student reflected:

When placed in the outreach group, I soon realized that it was in this group where the real action was going to be. From phone calls to the late night run to Kinko's, I have found that there is more detail to this project than my Elvis paint-by-numbers. . I I often wondered why I am putting miles on my car and losing sleep.... My wondering ended ... the first day we went out postering on Moody Street. I found out that I love this kind of stuff! ... Being out there, talking to people and visiting places that are outside my small universe stimulates and intrigues thinking and points of view. It is so easy to ignore the issue of immigration from the outside, but I found such ignorance impossible when brought inside and welcomed. When handing a poster to a shop owner from India I noticed a smile on his face and the questions started. He asked a broad range of questions, from how much we are charging for this service (nothing) to how many people he can bring along. The final question is the one that opened my eyes. In a heavy accent he asked, "why are we doing this if there is no money in it for us and we are already citizens?" I told him that hard work and helping others sometimes go well together, even without a paycheck.

Collaboration with community organizations is essential to C-Day preparations. Two weeks prior to C-Day, about twenty immigrants in Waltham attend workshops at local CBOs. In one instance, two students from the outreach committee and I engaged the community in discussion about the requirements for naturalization, the legal process, and the mechanics of C-Day. A question and answer session followed, as one student recounted:

One experience that stands out in my mind is the workshop we held. I was completely taken aback when my expectations faced reality that evening. It is hard to put into words my feelings that night. The project became "real." My well organized notes and outline style preparation could have been left home, these people became faces and names to me, not just an abstract group victimized by new legislation. Sure it was frustrating not to have things go the way that we had planned and not be able to speak Spanish but, things turned out better than we hoped. Talking to a Haitian family, I learned about the fears they faced, not about politics and big business, but about being able to put food on the table, a doctor's visit when their child is sick, and a sense of pride combined with a commitment to hard work. These are not abstract ideas, this is what most of us take for granted and forget that 
not everybody is in the same boat. I really feel that I, we, have a certain responsibility not to forget and to help whenever and wherever possible.

Although not all students achieve the expectations set out for them in this project, their struggle in the early stages are to move beyond their own biographies and overcome feelings of inadequacy and disinterest. Most students engage their work along these lines; some of them of course do not. Gradually, the process begins to show results. As many students find they are up to the challenge, they begin working in a collaborative spirit. They find the time to meet and begin to create a social product. One student claimed:

\begin{abstract}
This (project) is all about a group working together towards making a difference in the community, and creating a new program at the college. What makes it more gratifying is that without the other-students and immigrants - our goals would not have been achieved.
\end{abstract}

By the project's end, the first student's fears had been replaced by a sense of wonder that the project really did make a difference in the lives of community residents.

I never saw so many smiles on people's faces. I didn't feel uncomfortable or timid at all at that point to answer any questions they had. ... I even got a chance to speak a little Portuguese with somebody in their 50s who was there with his sister to bring their 82 year old mother to fill out her application. He must have shaken my hand and said thank you about 50 times.

Similarly, the second student's initial fear turned to "an adrenaline rush" as all the plans became real.

\footnotetext{
I was not expecting to see what I saw when I opened those doors. The room looked fantastic. It was exactly as envisioned on the classroom board. The tables were set up just as imagined, there were posters, signs, and flags. I was in a state of disbelief ... unaware of our potential. I just did not give us enough credit. ... By 9:30, people were arriving, adrenaline was rush-
}

ing, excitement was building. All our months of hard work and commitment finally realized. Let the Games begin.

\section{Discussion and Conclusion}

CSL is designed to challenge quiescent students and citizens to become stakeholders in their own communities. To be successful, it must also address the causes of such quiescence and anomie. CSL is meant to overcome three weaknesses of traditional pedagogy that combine to produce an apathetic citizenry: 1 ) Academic disciplines have become increasingly isolated in this century with the development of the modern research university and the corresponding development of discrete areas of specialization; 2) "Rigor" within higher education has progressively come to mean isolated specialization within a discipline, and 3 ) Pedagogical rigor has come to mean those techniques that support this isolation.

The concept-centered basis of traditional classroom instruction alone is inadequate to provide education for the well-prepared citizen.

Through symbolic presentations, students learn methods of collecting information, but not methods of processing and critically evaluating that information in a real-time setting (Aronowitz and Giroux 1985). While professors present information and evoke responses to questions, the merits and shortcomings of different social science perspectives are not carefully tested, nor are the teacher's own interpretations of specific knowledge (Gimenez 1989, 185). As professors lead the class, students primarily receive information, take notes, memorize facts, and prepare for exams. In this situation, "the professor is empowered to speak and to act while the student is constrained to listen, to take notes, and to accept. The result ... victimizes students by denying their competence and undermining their sense of subjective agency, ultimately reproducing classrooms and cultures of silence" (Wright 1989, 194).

Such factors hardly contribute a training ground for proactive citizen- ship. Rather, they reinforce higher education's increasing isolation from the real world. As the ever-prescient Alexis de Tocqueville warned, "in disengaging the classroom from realworld settings, schools ... fail to do their job and democracy ... fail(s) to secure the responsible citizens it needs to flourish" (quoted in Barber 1997). Tocqueville hits the mark. According to a recent Times-Mirror poll (1990), young citizens "know less ... about news and public affairs than any other generation of Americans in the past fifty years." Moreover, only a third of Americans trust the government to do the right thing, according to a 1998 poll conducted by the Pew Research Center for the Public and the Press. A recent Carnegie Foundation report claims, "If there is a crisis in education in the United States today, it is less that test scores have declined than it is that we have failed to provide the education for citizenship that is still the most important responsibility of the nation's schools and colleges" (Newman 1985, 3:1).

If Jurgen Habermas is correct in claiming that "the institutions of constitutional freedom are only worth as much as a population makes of them" (quoted in Calhoun 1992, 7), then America's democratic institutions are endangered by too narrow a focus on passive legal-status citizenship. Harkavy and Puckett give voice to this concern as it relates to the role of higher education, writing "Colleges and universities can no longer afford the luxury of being inward looking, relatively selfcontained and unconcerned about producing useful knowledge 'for the betterment of humanity.' Nor can they operate with such a threadbare moral purpose" $(1992,32)$. Under such conditions, a crucial opportunity is lost to provide skills and direction for a multi-faceted and active role for prospective citizens in the civic marketplace (Dewey 1916; Coleman 1977).

CSL provides just such a process of active learning for citizenship that prepares young adults for lives of active participation. Such CSL projects as C-Day are not without their problems. Some students com- 
plain about "free riders" in their midst and that the process was too messy, inefficient, and lacking in direction. A couple of students contended that CBO's were not serious about collaborating with college students. Others found it difficult to take the time from traditional school work and jobs. Involvement in the project does not mean that all the students come to value becoming fully proactive citizens. CSL is not meant to indoctrinate students to favor immigration. It encourages critical inquiry about the nuances of immigration and citizenship-why it is, for example, that a nation of immigrants has always been ambivalent about immigration? It also provides tools for enhancing tolerance, engaging people from different cultures, problem solving, reflection, and critical inquiry. Even opponents of immigration recognize they will benefit from the skills they gained while participating in CSL, and, given the opportunity, they say they would do it again.

\section{Notes}

1. As stakeholders in the civic process, students must gain tools for leadership and perform responsibly and professionally and be accountable to their neighbors for their actions. Such are the factors comprising a proactive, socially oriented citizenship.

2. I acknowledge the active participation of the students enrolled in my spring 1997 Politics of Immigration class at Bentley College, and extend special thanks to Adam Hall, Anna Alvarado, Rose Milliance, and Carolina Barahona for their leadership. I also need to recognize Jim Ostrow and the Bentley Service Learning Center, Christine Williams, Marion Bishop, and Lucille Ponte for their support and editorial assistance.

3. For instance, my own government elective on urban politics includes a CSL module. One
English department class on dominant and minor discourse has added a module on immigration to integrate CSL, and a marketing class has included projects for students to create advertising campaigns for C-Day and BIAP.

4. In a cluster, students register for two or three linked courses simultaneously. Two clusters designed for spring 1998, "Crossing Borders: Identity, Immigration and Diversity" and "U.S. Culture and Immigration," have CSL components.

5. A fourth credit option is a one-credit course that is attached to a three-credit course. Students enrolled in fourth credit CSL courses commit to additional hours on a CSL project and produce a written or oral report, as agreed upon with the professor.

6 . In the asylum project, about one dozen stu- dents work at one refugee rights organization in Cambridge, Massachusetts. The students engage asylum applicants in any of three ways. They may choose to work with individual applicants on their asylum cases, work with groups of applicants in asylum clinics, or work with clients applying for employment authorization.

7. Bentley holds a weekly ESL discussion group and provides transportation to the college for immigrants from two community organizations. Participants include 10 to $15 \mathrm{CSL}$ students and about 25 ESL students. CSL students who receive $E S L$ training may also choose to tutor and assist in ESL classes at community sites.

8. Citizenship classes prepare immigrants to take the citizenship exam. The classes cover topics in American government and history.

\section{References}

Barber, Benjamin. 1997. "Afterword." In Experiencing Citizenship: Concepts and Models for Service-Learning in Political Science, ed. Richard Battistoni and William Hudson. Washington, DC: American Association for Higher Education.

Battistoni, Richard 1996. "Service Learning as Civic Learning: Lessons We Can Learn From Our Students." Paper presented at the annual meeting of the Northeastern Political Science Association, Boston.

—, and William Hudson. 1997. "Introduction." In Experiencing Citizenship Concepts and Models for Service-Learning in Political Science, ed. Richard Battistoni and William Hudson. Washington, DC: American Association for Higher Education.

Becker, Theodore L., and Richard Couto, eds. Teaching Democracy by Being Democratic. New York: Praeger.

Calhoun, Craig. 1992. Habermas and the Public Sphere. Cambridge, MA: MIT Press.

Coleman, James S. 1977. "Differences between Experiential and Classroom Learning." In Experiential Learning: Rationale, Characteristics, and Assessment, ed. Morris T. Keaton. San Francisco: Jossey-Bass.

Cruz, Nadinne. 1997. "Lifting As We Rise: Social Justice and Civic Participation." Presented at the Association of American Colleges and Universities Conference,
Community Service and Learning: Working for Democracy, Waltham, MA.

Dewey, John. 1916. Democracy and Education. New York: MacMillan.

Farr, James. 1997. "Political Theory." In Experiencing Citizenship. In Experiencing Citizenship: Concepts and Models for Service-Learning in Political Science, ed. Richard Battistoni and William Hudson. Washington, DC: American Association for Higher Education.

Gimenez, Martha E. 1989. "Silence in the Classroom: Some Thoughts About Teaching In the 1980s." Teaching Sociology 22: 319-27.

Harkavy, Ira, and John Puckett. 1992. "Universities and the Inner Cities." Planning for Higher Education 20:20-33.

Hutchings, Pat, and Allen Wutzdorff. 1988. "Experiential Learning across the Discipline: Assumptions and Principles." In Knowing and Doing: Learning Through Experience, ed. Pat Hutchings and Allen Wutzdorff. San Francisco: Jossey Bass.

Kilpatrick, William H. 1918. "The Project Method." Teacher's College Record 19(September): 319-35.

Kymlicka, Will, and Wayne Norman. 1994. "Return of the Citizen: A Survey of Recent Work on Citizenship Theory." Ethics 104(January): 352-81.

MacKnight, John. 1995. Careless Society: Community and its Counterfeits. New York: Harper Collins.
Markus, Gregory B. 1997. "Community ServiceLearning as Practice in the Democratic Political Arts. In Experiencing Citizenship: Concepts and Models for Service-Learning in Political Science, ed. Richard Battistoni and William Hudson. Washington, DC: American Association for Higher Education.

May, Marlynn, and Robert Koulish. 1998. "Teaching at the Border of Pedagogy: A Case Study in Teaching-Learning." Teaching Sociology.

Newman, Frank. 1985. Higher Education and the American Resurgence. Princeton: Carnegie Foundation for the Advancement of Teaching.

Pierson, Christopher. 1991. Beyond the Welfare State: The New Political Economy of Welfare. University Park, PA: Pennsylvania State University.

Stember, Marilyn. 1991. "Presidential Address: Advancing the Social Sciences Through Interdisciplinary Enterprise." The Social Science Journal 28.

Tocqueville, Alexis de. 1945. Democracy in America. New York: Vintage Books.

Wright, Richard A. 1989, "Toward A Theoretical Conceptualization of 'Silence in the Classroom': A Response to Gimenez " Teaching Sociology 17:194-96. 